\title{
Involvement of Pain Associated Anxiety in the Development of Morphine Tolerance in Formalin Treated Mice
}

\author{
A.F.M. Mohibur Rahman, Masakatsu Takahashi and Hiroshi Kaneto \\ Department of Pharmacology, Faculty of Pharmaceutical Sciences, Nagasaki University, 1-14, Bunkyo-machi, Nagasaki 852, Japan \\ Received March 11, 1994 Accepted May 10, 1994
}

\begin{abstract}
The mechanism underlying the previous findings that the development of antinociceptive tolerance to morphine was significantly delayed in the presence of inflammatory pain induced by formalin was examined. Measurements of the pain threshold at different time intervals have shown that pain lasts around one week in the formalin treated mice. A single dose of indomethacin $(10 \mathrm{mg} / \mathrm{kg}$ ) or aspirin ( 400 $\mathrm{mg} / \mathrm{kg}$ ), $30 \mathrm{~min}$ before formalin injection, and daily $400 \mathrm{mg} / \mathrm{kg}$ of aspirin had no effects on the pain threshold or swelling, and it also did not affect the delay of morphine tolerance development. Daily administration of diazepam, $1 \mathrm{mg} / \mathrm{kg}, 1 \mathrm{hr}$ before morphine injection completely abolished the delay. This effect was antagonized by $2 \mathrm{mg} / \mathrm{kg}$ of flumazenil, administered $15 \mathrm{~min}$ before diazepam injection. These results suggest that pain-associated anxiety participates in the delay of morphine tolerance development and consequently the benzodiazepine-receptor complex plays a role in the development of morphine tolerance during a painful state.
\end{abstract}

Keywords: Chronic pain, Formalin, Anti-inflammatory drug, Morphine tolerance, Anxiety

It is reported that patients with pain, such as chronic abdominal or back pain (1) or various types of chronic pain including cancer pain (2), were able to receive long term treatment with opiates without the development of analgesic tolerance. Supporting these reports, we found that the development of morphine tolerance was significantly delayed in an animal model of inflammatory pain induced by formalin (3).

In contrast, we also found that the development of tolerance was not influenced in mice treated with adjuvant (3). Likewise, Kayser and Guilbaud (4) and Kayser et al. (5) have observed the development of complete tolerance to morphine in arthritic animals. Thus, whether chronic pain or some kinds of nociceptive stimuli can modify the development of tolerance to narcotics is still a controversial problem.

For the continuation of our previous report, we have examined the factors involving the delay of morphine tolerance development, i.e., the time course and intensity of pain and inflammatory swelling, in the formalin-treated mice. In addition, the possible involvement of benzodiazepine (BZP)-receptor-mediated mechanisms in the delay was examined since pain is essentially accompanied by anxiety.

\section{MATERIALS AND METHODS}

Animals

Male mice of the ddY strain, weighing $18-20 \mathrm{~g}$, were housed in plastic cages with free access to food and water. They were kept in a temperature-controlled room at $22 \pm 1{ }^{\circ} \mathrm{C}$ and maintained on a 12 -hr light/dark cycle. They were used in the experiments after reaching a weight of about $25 \mathrm{~g}$.

Drugs

Morphine-HCl (Takeda, Osaka), diazepam (Cercine $\mathrm{e}^{\mathbb{Q}}$, Takeda), flumazenil (a gift from Nihon-Roche, Kamakura), indomethacin (Kissei, Nagano), aspirin (Venopirin $^{\circledR}$, Midorijuji, Osaka) and formalin (Katayama, Osaka) were used. Indomethacin was suspended in $1 \%$ CMC (carboxymethyl cellulose).

\section{Induction of pain and assessment of inflammation}

A single $20-\mu l$ injection of 1 or $2 \%$ formalin was given into the dorsal part of the left hind paw. The thickness of the inflammed paw was measured with slide calipers.

\section{Measurement of pain threshold}

Pain threshold was measured by a slightly modified 
Randall-Selitto apparatus (6). The gradually increasing pressure was applied on the inflammed paw. Biting at the pressure pointer, vocalization or vigorous jerking were the indicators of pain. To avoid tissue damage, pressure was fixed to a maximum of $250 \mathrm{~g}$ unless the animals started to bite or vocalize before this weight was reached.

\section{Assessment of antinociceptive effect}

The antinociceptive effect was measured at an interval of $15 \mathrm{~min}$ for $90 \mathrm{~min}$ after s.c. injection of $10 \mathrm{mg} / \mathrm{kg}$ morphine by the modified Haffner's method (7).

\section{Assessment of tolerance}

The antinociceptive effect of morphine was determined daily for 5 or 8 days. The antinociceptive effect was expressed as the area under the time-response curve (AUC), by plotting the increase in response time (sec) on the ordinate and the time interval ( $\mathrm{min}$ ) on the abscissa. A significant decrease of AUC, as compared with the 1st day, is indicative of tolerance development.

\section{Statistical analyses}

Results were expressed as the mean \pm S.E. Following analysis of variance for repeated measures of the overall data to assess statistical significance, differences between the individual mean values in different groups were analyzed by Dunnett's test. Data for two individual means were also analyzed by Student's $t$-test.

\section{RESULTS}

\section{Development of tolerance}

Daily injection of morphine at $10 \mathrm{mg} / \mathrm{kg}$, s.c. resulted in the development of tolerance to the effect on the 4th day in both the saline- and $1 \%$ formalin-treated groups. Meanwhile, the development of tolerance was significantly delayed until the 5 th day in the $2 \%$ formalin-treated group compared with the control group; however, from the 6th day, the gradual reduction of the antinociceptive effect lead to the development of tolerance within another 2 days (Fig. 1).

\section{Paw swelling}

The swelling in the formalin-treated paw continued for more than 10 days (Fig. 2) with a pathological scar that appeared at the beginning of the 2 nd week and detached by the end of 2 nd week (within 12 to 14 days), when the paw size became normal and there was no significant difference between the control and formalin-treated groups.

\section{Pain threshold}

Pain threshold was determined before and at $24 \mathrm{hr}$ and 6 and 10 days after the injection of $2 \%$ formalin, the con-

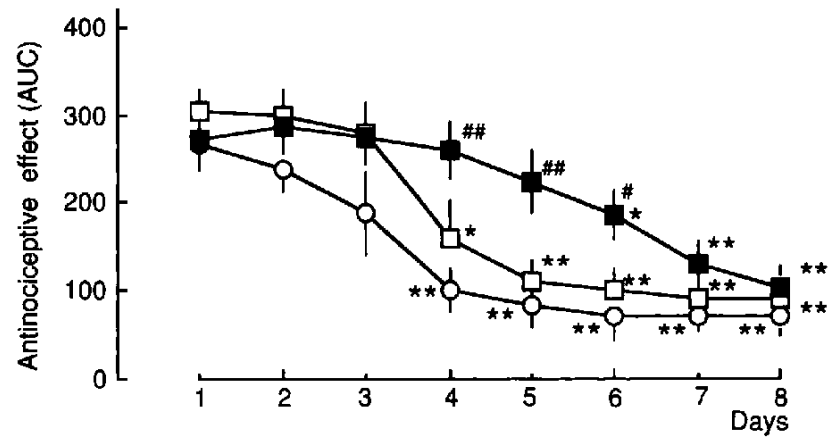

Fig. 1. Development of tolerance to morphine antinociception in the formalin-treated mice. Two hours after the injection of $1 \%$ ( $\square$ ) or $2 \%$ ( $\square$ ) formalin, morphine at $10 \mathrm{mg} / \mathrm{kg}$, s.c. was administered daily; and subsequently, the antinociceptive effect was measured by the tail-pinch method for 8 successive days. The control group ( $O$ ) was treated with saline instead of formalin. Each point indicates the mean \pm S.E. $(n=16)$. Significantly different from the corresponding value on the 1 st day, ${ }^{*} \mathbf{P}<0.05,{ }^{* *} P<0.01$. Significantly different from the effect in the control group on the respective days, ${ }^{H} \mathrm{P}<0.05$, ${ }^{*} \mathrm{P}<0.01$,

centration at which the development of morphine tolerance was delayed. Twenty-four hours after the formalin injection, the pain threshold was significantly lower compared with the pre-pain threshold and that of the salinetreated control group. On the 6th day, it was also significantly lower, but tended to increase. On the 10th day, there were no significant differences between the control and formalin-treated groups, indicating the recovery from pain (Fig. 3).

\section{Effects of anti-inflammatory drugs}

Pain threshold was also determined in the formalin

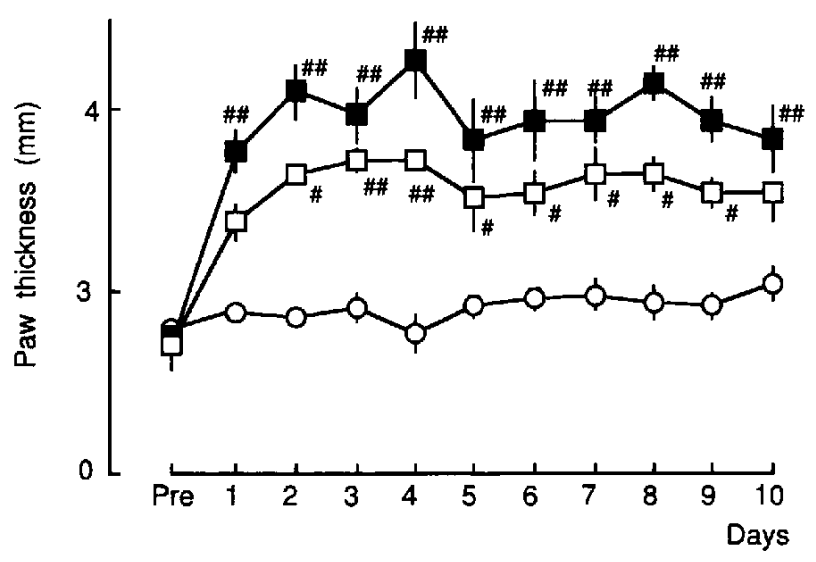

Fig. 2. Induction and duration of inflammation after a single injection of formalin. Twenty microliters of $1 \%(\square)$ or $2 \%$ ( $\square$ ) formalin was injected into the dorsal part of hind paw. Each point indicates the mean \pm S.E. $(n=6)$. Significantly different from the effect in the saline-treated control group $(\bigcirc)$ on the respective days, ${ }^{\sharp} \mathbf{P}<0.05$, ${ }^{\#} \mathrm{P}<0.01$. 

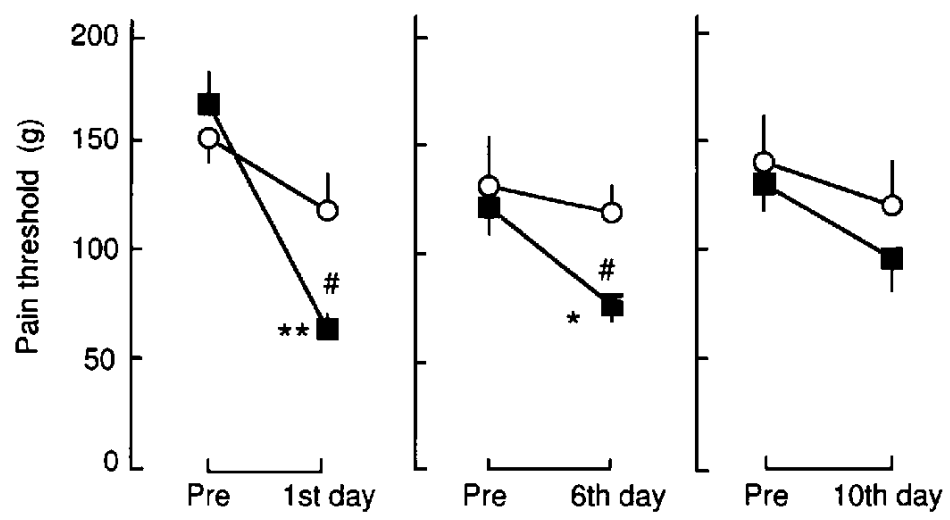

Fig. 3. Measurement of pain threshold at different time-intervals in formalin-treated mice. The pain threshold using a RandallSelitto apparatus was measured $24 \mathrm{hr}$ (1st), 6 days (6th) or 10 days (10th) after a single injection of $20 \mu \mathrm{lof} 2 \%$ formalin ( $\square$ ). Different groups of mice were used for each measurement. Each point indicates the mean \pm S.E. $(n=10-16)$. Significantly different from the corresponding value measured before treatment (Pre), ${ }^{*} \mathrm{P}<0.05,{ }^{* *} \mathrm{P}<0.01$. Significantly different from the saline-treated control group $(\bigcirc), " \mathrm{P}<0.05$.
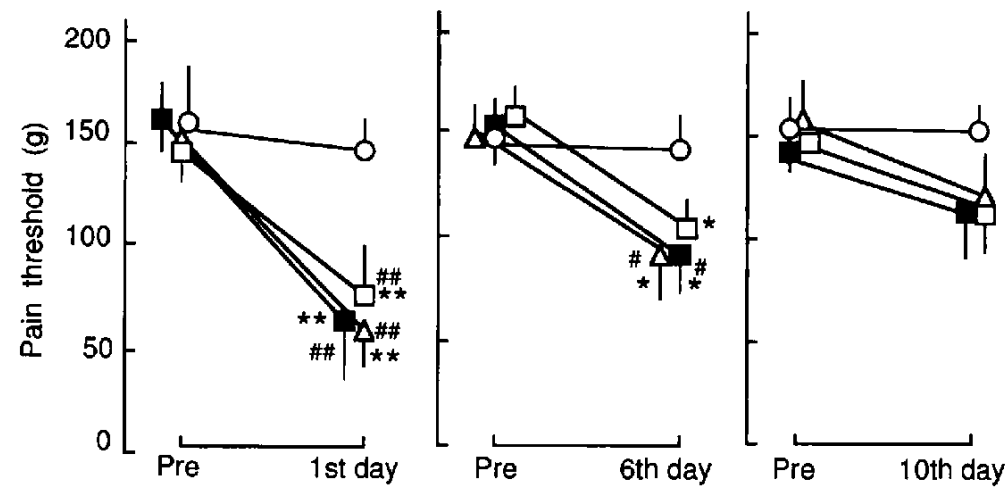

Fig. 4. Effects of indomethacin and aspirin on the pain threshold in the formalin-treated groups. A single dose of indomethacin $(\square)$ at $10 \mathrm{mg} / \mathrm{kg}, 30 \mathrm{~min}$ before the injection of $2 \%$ formalin, or daily injection of aspirin ( $\triangle$ ) at $400 \mathrm{mg} / \mathrm{kg}, \mathrm{starting} 30$ min before the formalin injection, was administered in the formalin-treated mice. The pain threshold was measured $24 \mathrm{hr}$ (1st), 6 days (6th) or 10 days (10th) after the formalin injection or $2 \mathrm{hr}$ after the injection of aspirin on the test day. The formalin ( $\square$ )and saline $(O)$-treated control groups were given saline instead of indomethacin and aspirin. Each point indicates the mean \pm S.E. $(n=10-12)$. Significantly different from the corresponding value measured before treatment $(\operatorname{Pre}),{ }^{*} \mathrm{P}<0.05$, ${ }^{* *} \mathrm{P}<0.01$. Significantly different from the saline control group, ${ }^{*} \mathrm{P}<0.05,{ }^{* *} \mathrm{P}<0.01$.
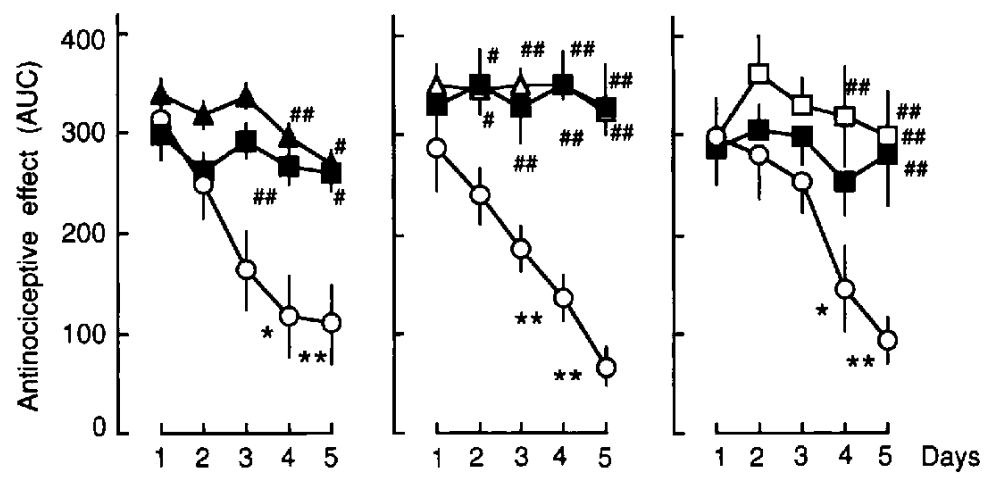

Fig. 5. The effect of anti-inflammatory drugs on the delay of the development of tolerance to morphine antinociception in the formalin-treated mice. Two hours after the injection of $2 \%$ formalin, morphine at $10 \mathrm{mg} / \mathrm{kg}$, s.c. was administered daily; and subsequently, the antinociceptive effect was measured by the tail-pinch method for 5 successive days. A single dose of indomethacin $(A)$ at $10 \mathrm{mg} / \mathrm{kg}$ or aspirin $(\triangle)$ at $400 \mathrm{mg} / \mathrm{kg}, 30 \mathrm{~min}$ before the injection of $2 \%$ formalin, or aspirin $(\square)$ at $400 \mathrm{mg} / \mathrm{kg}$, $2.5 \mathrm{hr}$ before daily morphine at $10 \mathrm{mg} / \mathrm{kg}$, were administered. The formalin ( $\square$ )- and saline $(\bigcirc)$-treated control groups were given saline instead of indomethacin and aspirin. Each point indicates the mean \pm S.E. $(n=10)$. Significantly different from the corresponding value on the 1 st day, ${ }^{*} \mathrm{P}<0.05,{ }^{* *} \mathrm{P}<0.01$. Significantly different from the saline control on the respective days, ${ }^{\#} \mathbf{P}<0.05,{ }^{\# \#} \mathrm{P}<0.01$. 


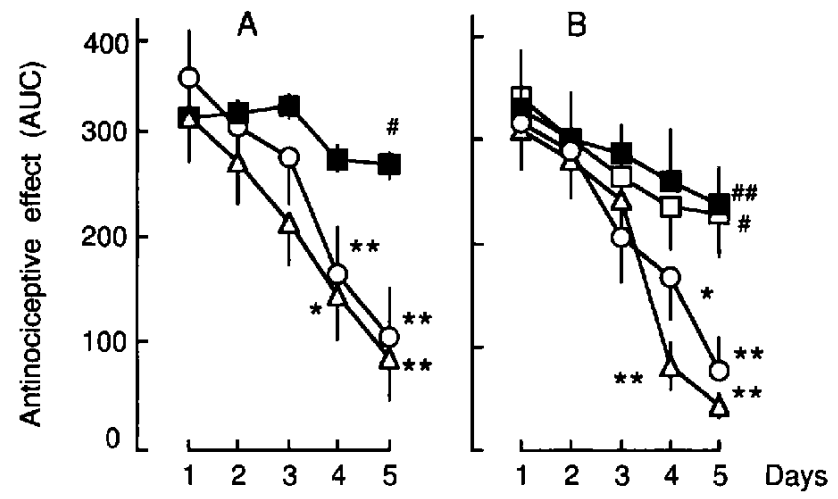

Fig. 6. The effect of diazepam and fumazenil on the delay of the development of tolerance to morphine antinociception in the formalin-treated mice. Diazepam $(\triangle)$ at $1 \mathrm{mg} / \mathrm{kg}$, s.c., $60 \mathrm{~min}$ before daily morphine at $10 \mathrm{mg} / \mathrm{kg}$, were administered in the formalin treated mice (A). Flumazenil $(\square$ ) at $2 \mathrm{mg} / \mathrm{kg}$, i.p., was injected 15 min before diazepam injection (B). The formalin ( $\square$ )- and saline ( $O$ )-treated control groups were given saline instead of diazepam and flumazenil. For other details, refer to Fig. 5. Each point indicates the mean $t$ S.E. $(n=10)$. Significantly different from the corresponding value on the 1 st day, ${ }^{*} \mathrm{P}<0.05,{ }^{* *} \mathrm{P}<0.01$. Significantly different from the saline control on the respective days, ${ }^{n} \mathrm{P}<0.05$, ${ }^{\# \#} \mathbf{P}<0.01$.

$(2 \%)$ groups treated with indomethacin or daily aspirin. These drugs had no effect on the pain threshold (Fig. 4). Daily treatment with indomethacin resulted in the death of mice in 2 or 3 days even at the lowest dose used in this experiment.

The mice were given a single dose of indomethacin $(10$ $\mathrm{mg} / \mathrm{kg}$, p.o.) or aspirin ( $400 \mathrm{mg} / \mathrm{kg}$, i.p.), $30 \mathrm{~min}$ before $2 \%$ formalin, or administered aspirin daily, $2.5 \mathrm{hr}$ before s.c. morphine $(10 \mathrm{mg} / \mathrm{kg})$, for 5 days. These treatments had no effects on the delay of morphine tolerance development in formalin treated mice (Fig. 5).

\section{Effects of diazepam and fumazenil}

Daily injection of diazepam at $1 \mathrm{mg} / \mathrm{kg}$, s.c., $1 \mathrm{hr}$ before morphine injection, reversed the delay in morphine tolerance development in the formalin (2\%)-treated mice. This reversal of delay by diazepam was antagonized by 2 $\mathrm{mg} / \mathrm{kg}$ of i.p. flumazenil $15 \mathrm{~min}$ before diazepam injection. Neither diazepam nor flumazenil affected the antinociception by morphine itself on the 1st day (Fig. 6).

\section{DISCUSSION}

The time course of the delay in morphine tolerance development in the $2 \%$ formalin-treated mice was well matched with that of the existence of pain which was measured at different time intervals. This result agrees well with our previous study showing that daily injection of morphine starting from 6 days after the formalin injec- tion resulted in the development of morphine tolerance (3), indicating that pain plays an important role in the mechanisms. Additionally, it is reported that in the formalin test, tolerance to morphine analgesia is very slow or non-existent, and conditioned or behavioral tolerance does not occur (8).

Meanwhile, the swelling developing immediately after formalin injection basically continues for 5 to 7 days, and then a depilated scar begins which lasts for a further week (9). Thus, the statistically significant difference between the formalin-treated and control groups at the 2nd week is partly due to the scar that is detached normally at the end of 2 nd week (within 12 to 14 days), and it is rather difficult to give a plausible explanation for the mechanism from the swelling, which is not parallel with the pain threshold. Conversely, the swelling or inflammatory process can be accountable for the pain, and the appearance of scar formation at the beginning of the 2 nd week indicates not only the healing of inflammation but also recovery from pain sensation that is well matched with our both previous and present reports.

To investigate the mechanism underlying the delay in the formalin-treated mice, peripheral anti-inflammatory drugs were used to prevent the inflammation and subsequent inflammatory pain; however, they had no effects on the pain threshold or on the inflammatory swelling and did not affect the delay in morphine tolerance development in the group. It is well known that formalin produces a biphasic pain response after its injection $(9-11)$ : the 1 st or early phase due to direct stimulation of nociceptors and the 2nd or tonic late phase due to an inflammatory response, and these phases represent two independent processes that are mediated by separable neural systems $(12-14)$. Anti-inflammatory agents reduce pain behavior only in the late phase $(9-15)$ resulting from the inflammatory response and disappearing within two hours after injection; however, there probably exists pain generated from the tissue damage that subsequently produces a chronic inflammatory status (9). Thus, the failure of anti-inflammatory drugs to affect the delay may be consistent with the assumption that these drugs are ineffective in suppressing such pain due to tissue damage. Another reason may be the higher concentration of formalin (more than 1\%) used, at which the anti-inflammatory effects of the drugs could not be observed because of the severe tissue destruction which also caused lingering pain $(9,16)$. Besides the inflammation, the late phase of the formalin test is dependent upon prolonged changes in central nervous system function produced by neural activity that is generated during the transient early phase $(12,14)$. Therefore, the initial pain stimuli that modulated the central mechanism of the pain system and subsequently the development of morphine tolerance was not affected by 
the peripheral anti-inflammatory drugs $(12,14)$.

Inflammatory pain that lasted around one week might produce a chronic status of anxiety. Diazepam has been used as an anxiolytic drug in both clinical and experimental fields of research. The antinociceptive effect of morphine was not altered by $1 \mathrm{mg} / \mathrm{kg}$ of diazepam, which is also supported by another report (17). Interestingly, daily administration of diazepam prevented the delay of morphine tolerance in the formalin-treated mice, indicating that pain associated anxiety plays a role in this phenomenon. In humans, diazepam reduces the analgesia induced by anticipation of exposure to painful (foot-shock) stress (18). Diazepam extinguished the suppression of morphine tolerance development by psychological stress (19). Additionally, $\beta$-CCE, an inverse agonist for benzodiazepine receptors with experimentally anxiogenic properties (20), completely suppressed the development of tolerance to morphine, and this blocking effect was antagonized by flumazenil (19). The development of morphine tolerance was modified in the presence of inflammatory pain, which was first assumed to have resulted from pain itself. However, reversal of the delay by diazepam and its antagonism by flumazenil confirmed the involvement of pain-associated anxiety in the suppression of morphine tolerance development in formalin-treated mice, and these findings are evidence supporting the participation of the benzodiazepine-receptor complex in the development of morphine tolerance during a painful state.

\section{REFERENCES}

1 Portenoy RK and Foley KM: Chronic use of opioid analgesics in non-malignant pain: Report of 38 cases. Pain 25, 171-186 (1986)

2 Melzack R: Human versus pain. The dilemma of morphine. In Advances in Pain Research and Therapy, Edited by Sicuteri $F$, Terenius L, Vecchiet L, Maggi CA, Nicolodi $M$ and Alessandri M, Vol 20, pp 149-159, Raven Press, New York (1992)

3 Rahman AFMM, Takahashi $M$ and Kaneto $H$ : Development of tolerance to morphine antinociception in mice treated with nociceptive stimulants. Jpn J Pharmacol 63, 59-64 (1993)

4 Kayser V and Guilbaud G: Can tolerance to morphine be induced in arthritic rats? Brain Res 334, 335-338 (1985)

5 Kayser V, Neil A and Guilbaud G: Repeated low doses of morphine induce a rapid tolerance in arthritic rats but a potentia- tion of opiate analgesia in normal animals. Brain Res 383, $392-396$ (1986)

6 Randall LO and Selitto JJ: Method for measurement of analgesic activity on inflamed tissue. Arch Int Pharmacodyn Ther 111, 409-419 (1957)

7 Takagi $\mathrm{H}$, Inukai $\mathrm{T}$ and Nakama $\mathrm{M}$ : A modification of Haffner's method for testing analgeisc. Jpn J Pharmacol 16, $287-294$ (1966)

8 Abbott FV, Franklin KBJ, Ludwick RJ and Melzack R: Apparent lack of tolerance in the formalin test suggests different mechanisms for morphine analgesia in different types of pain. Pharmacol Biochem Behav 15, 637-640 (1981)

9 Rosland JH, Tjolsen A, Maehle B and Hole K: The formalin test in mice: Effect of formalin concentration. Pain 42, 235-242 (1990)

10 Dubuisson D and Dennis SG: The formalin test: A quantitative study on the analgesic effects of morphine, meperidine and brain stem stimulation in rats and cats. Pain 4, 161 - 174 (1977)

11 Shibita $\mathbf{M}$, Ohkubo T, Takahashi $\mathrm{H}$ and Inoki R: Modified formalin test: Characteristic biphasic pain response. Pain 38, $347-352$ (1989)

12 Vaccarino AL, Marek $P$ and Liebeskind JC: Stress-induced analgesia prevents the development of the tonic, late phase of pain produced by subcutaneous formalin. Brain Res 572, 250-252 (1992)

13 Abbott FV, Melzack R and Samuel C: Morphine analgesia in the tail-flick and formalin pain tests is mediated by different neural systems. Exp Neurol 75, 644-651 (1982)

14 Coderre TJ, Vaccarino AL and Melzack R: Central nervous system plasticity in the tonic pain response to subcutaneous formalin. Brain Res 535, 155-158 (1990)

15 Hunskaar S and Hole K: The formalin test in mice: Dissociation between inflammatory and non-inflammatory pain. Pain $\mathbf{3 0}$, $103-114$ (1987)

16 Murry $\mathrm{CW}$, Porreca $\mathrm{F}$ and Cowan N: Methodological refinements to the mouse paw formalin test. An animal model of tonic pain. J Pharmacol Meth 20, 175-186 (1988)

17 Shannon HE, Holtzman SG and Davis DC: Interaction between narcotic analgesics and benzodiazepine derivatives in the mouse. J Pharmacol Exp Ther 199, 389-399 (1976)

18 Willer JC and Earnst M: Diazepam reduces stress-induced analgesia in humans. Brain Res 362, 398-402 (1986)

19 Tokuyama S, Takahashi $\mathrm{M}$ and Kaneto $\mathrm{H}$ : Blockade of the development of analgesic tolerance to morphine by psychological stress through benzodiazepine receptor mediated mechanism. Jpn J Pharmacol 51, 425-427 (1989)

20 Skolnick P, Crawley JN and Glowa JR: $\beta$-Carboline-induced anxiety states. Psychopharmacology (Berlin) 17, Supp 3, 52-60 (1984) 